\title{
Development and validation of an analytical method for the simultaneous determination of cocaine and its main metabolite, benzoylecgonine, in human hair by gas chromatography/mass spectrometry
}

\author{
M. Barroso ${ }^{1 *}$, M. Dias ${ }^{1}$, D. N. Vieira ${ }^{2}$, J. A. Queiroz ${ }^{3}$ and M. López-Rivadulla ${ }^{4}$ \\ ${ }^{1}$ Instituto Nacional de Medicina Legal - Delegação do Sul, Rua Manuel Bento de Sousa, 3, 1150-219 Lisboa, Portugal \\ ${ }^{2}$ Instituto Nacional de Medicina Legal, Largo da Sé Nova, 3000-213 Coimbra, Portugal \\ ${ }^{3}$ Universidade da Beira Interior - Centro de Investigação em Ciências da Saúde, Av. Infante D. Henrique, 6201-506 Covilhã, Portugal \\ ${ }^{4}$ Instituto de Medicina Legal de Santiago de Compostela, San Francisco s/n, 15782 Santiago de Compostela, Spain
}

Received 17 July 2008; Revised 26 August 2008; Accepted 27 August 2008

\begin{abstract}
A new, simple and rapid procedure has been developed and validated for the determination of cocaine and its main metabolite, benzoylecgonine, in human hair samples. After extraction from within the hair matrix by a mixture of methanol/hydrochloric acid $(2: 1)$ at $65^{\circ} \mathrm{C}$ for $3 \mathrm{~h}$, and sample cleanup by mixed-mode solid-phase extraction (SPE), the extracts were analyzed by gas chromatography/mass spectrometry (GC/MS), after derivatization with $N$-methyl- $N$-(trimethylsilyl)trifluoroacetamide with $5 \%$ chlorotrimethylsilane. Using a sample size of only $20 \mathrm{mg}$ of hair, limits of detection (LODs) and quantitation (LOQs) were, respectively, 20 and $50 \mathrm{pg} / \mathrm{mg}$ for cocaine, and 15 and $50 \mathrm{pg} / \mathrm{mg}$ for benzoylecgonine, achieving the cut-off values proposed by the Society of Hair Testing for the analysis of these compounds in hair. The method was found to be linear (weighing factor of $1 / x$ ) between the LOQ and $20 \mathrm{ng} / \mathrm{mg}$ for both compounds, with correlation coefficients ranging from 0.9974 to 0.9996 for cocaine; and from 0.9981 to 0.9994 for benzoylecgonine. Intra- and interday precision and accuracy were in conformity with the criteria normally accepted in bioanalytical method validation. The sample cleanup step presented a mean absolute recovery greater than $90 \%$ for both compounds. The developed method may be useful in forensic toxicology laboratories for the analysis of cocaine and benzoylecgonine in hair samples, taking into account its speed (only $3 \mathrm{~h}$ are required for the extraction of the analytes from within the matrix, whereas $5 \mathrm{~h}$ or even overnight extractions have been reported) and the low limits achieved (using a single quadrupole mass spectrometer, which is available in most laboratories). Copyright (C) 2008 John Wiley \& Sons, Ltd.
\end{abstract}

\begin{abstract}
Alternative specimens are gaining increasing relevance in toxicological analysis. Amongst these samples, hair plays a special role for several reasons, e.g. the fact that its collection is not invasive, its adulteration is difficult, and the windows of detection for certain drugs can be strongly enhanced. ${ }^{1-5}$ Hair is often called a timetable of drug exposure, and this characteristic represents an overwhelming advantage, since it allows segmental analysis, which assumes particular importance in workplace drug testing ${ }^{5,6}$ and drug-facilitated crimes. ${ }^{7,8}$

The Society of Hair Testing (SoHT) has proposed a number of guidelines for the analysis and results interpretation of cocaine and metabolites in hair samples, stating that cocaine should be present at a concentration above the cut-off value of $0.5 \mathrm{ng} / \mathrm{mg}$ and that at least one metabolite should be present at a concentration of $0.05 \mathrm{ng} / \mathrm{mg}$ or higher. ${ }^{9}$
\end{abstract}

*Correspondence to: M. Barroso, Instituto Nacional de Medicina Legal - Delegação do Sul, Rua Manuel Bento de Sousa, 3, 1150219 Lisboa, Portugal.

E-mail: mbarroso@dlinml.mj.pt
The analysis of cocaine and metabolites in hair usually begins with the quantitative extraction of the compounds from the matrix, which is the most time-consuming step in hair analysis. This can be achieved by several procedures, such as solvent or buffer extraction, ${ }^{10-15}$ enzymatic digestion, $^{16-20}$ or treatment with hydrochloric acid at different concentrations, ${ }^{21-28}$ using different temperatures and extraction time profiles.

However, care should be taken in this step, since spontaneous conversion of cocaine into its metabolite benzoylecgonine as an artifact during sample extraction, especially under strong alkaline conditions, has been documented. ${ }^{24,29,30}$

Several techniques for sample cleanup have been described, such as liquid-liquid extraction, ${ }^{31,32}$ solid-phase extraction (SPE), ${ }^{27,33-37}$ solid-phase microextraction, ${ }^{19,38}$ or supercritical fluid extraction, ${ }^{39}$ followed by either liquid or gas chromatography.

This paper describes a new gas chromatography/ mass spectrometry (GC/MS)-based analytical method for 
the quantitation of cocaine and its main metabolite benzoylecgonine in hair samples after a short $3 \mathrm{~h}$ acidic extraction followed by mixed-mode SPE. This extraction time provides a drastic time reduction compared with other published methods in which longer extraction times are used, ${ }^{14,15,19,25-28,40-42}$ allowing the complete sample analysis within 1 day and greater sample throughput. Moreover, low limits of detection and quantitation were obtained using only $20 \mathrm{mg}$ of sample, which make this technique useful in forensic toxicology laboratories, especially in situations where the sample volume is limited.

\section{EXPERIMENTAL}

\section{Reagents and standards}

Analytical standards, cocaine and benzoylecgonine, and their trideuterated analogues, were purchased from Cerilliant (Round Rock, TX, USA) in solution at a concentration of $1 \mathrm{mg} / \mathrm{mL}$. Methanol (HPLC grade), dichloromethane, n-hexane, 2-propanol, ammonium hydroxide, hydrochloric acid, sodium hydroxide and potassium dihydrogen phosphate (analytical grade) were obtained from Merck (Darmstadt, Germany).

$\mathrm{N}$-Methyl- $\mathrm{N}$-(trimethylsilyl)trifluoroacetamide (MSTFA) and chlorotrimethylsilane (CTMS) were purchased from Macherey-Nagel (Düren, Germany). Oasis ${ }^{\circledR}$ MCX (3 mL, $60 \mathrm{mg}$ ) extraction cartridges were obtained from Waters (Milford, MA, USA).

Working solutions at $10,1,0.4$ and $0.02 \mu \mathrm{g} / \mathrm{mL}$ of both compounds were prepared by proper dilution of the stock solutions with methanol. Working solutions of the internal standards at $10 \mu \mathrm{g} / \mathrm{mL}$ were prepared, also in methanol. All these solutions were stored light-protected at a temperature between 2 and $8^{\circ} \mathrm{C}$.

To prepare the $0.1 \mathrm{M}$ potassium dihydrogen phosphate solution, $13.61 \mathrm{~g}$ of potassium dihydrogen phosphate were weighed into a volumetric flask, and a final volume of $1 \mathrm{~L}$ was obtained with deionized water.

Sodium hydroxide $(4 \mathrm{M})$ was prepared by weighing $160 \mathrm{~g}$ of sodium hydroxide into a volumetric flask, and a final volume of $1 \mathrm{~L}$ was obtained with deionized water.

\section{Biological samples}

Blank hair used in the optimization experiments and validation was obtained from laboratory volunteers. Authentic samples belonging to drug addicts were collected at the beginning of autopsies performed at the Forensic Pathology Service of the National Institute of Legal Medicine - South Delegation, Lisbon, Portugal.

\section{Gas chromatographic conditions}

Chromatographic analysis was performed using an HP $6890 \mathrm{~N}$ gas chromatograph (Hewlett-Packard, Waldbronn, Germany), equipped with a model 5973 mass-selective detector (Hewlett-Packard). A capillary column (30 m $\times$ $0.25 \mathrm{~mm}$ i.d., $0.25 \mu \mathrm{m}$ film thickness) with $5 \%$ phenylmethylsiloxane (HP-5 MS) from J \& W Scientific (Folsom, CA, USA) was used.

The chromatographic conditions were as follows: initial oven temperature was $90^{\circ} \mathrm{C}$ for $2 \mathrm{~min}$, which was increased by $20^{\circ} \mathrm{C} \mathrm{min}^{-1}$ to $300^{\circ} \mathrm{C}$, held for $3 \mathrm{~min}$. The temperatures of the injection port and detector were 220 and $280^{\circ} \mathrm{C}$, respectively. The split injection mode was used (split ratio of 1:5), and helium with a flow rate of $0.8 \mathrm{~mL} \mathrm{~min}^{-1}$ was used as the carrier gas. The mass spectrometer was operated with a filament current of $300 \mu \mathrm{A}$ and electron energy of $70 \mathrm{eV}$ in the electron ionization (EI) mode. Quantitation was done in the selected ion monitoring (SIM) mode, and the ions were monitored at $m / z 82,182$ and 303 for cocaine, and at $m / z$ 82, $\underline{240}$ and 361 for benzoylecgonine (quantitation ions are underlined). For the internal standards, only one ion was monitored for each compound, at $m / z 185$ for cocaine- $d_{3}$ and at $m / z 243$ for benzoylecgonine- $d_{3}$.

The retention times were 11.7 and $12.0 \mathrm{~min}$ for cocaine and benzoylecgonine, respectively, obtaining good separation of both compounds.

\section{Preparation of soaked hair}

Because spiked hair does not simulate adequately an authentic hair sample, soaked hair was used for the optimization of extraction conditions, so that the drug could be actually extracted from within the matrix. Blank hair samples from five different origins were cut with a scissors. A $1 \mathrm{~g}$ pool of these samples was exposed to an aqueous cocaine solution at $100 \mu \mathrm{g} / \mathrm{mL}$, which was heated at $35^{\circ} \mathrm{C}$ for $72 \mathrm{~h}$. After this period, the hair was thoroughly washed with dichloromethane, deionized water and methanol. After the last wash, the hair was rinsed several times with methanol, until no drug could be detected in the wash solvent. The hair was then dried at $40^{\circ} \mathrm{C}$ under a gentle stream of $\mathrm{N}_{2}$.

Optimization experiments were performed in triplicate in $20 \mathrm{mg}$ aliquots of this pool.

Additional soaked hair samples were prepared at three concentration levels for the quality control (QC) samples for the precision and accuracy experiments. The concentrations of the solutions to which blank hair was exposed, and the concentrations obtained in hair (the mean of 15 measurements, in $\mathrm{ng} / \mathrm{mg}$ ), are shown in Table 1.

\section{Hair washing}

To avoid drug detection arising from environmental contamination, the hair was washed sequentially with dichloromethane, deionized water and methanol. The last wash was stored for further analysis.

\section{Drug extraction from hair}

The extraction procedure was optimized in a preliminary study (see Results and discussion section), and the final conditions were as follows. Hair $(20 \mathrm{mg}$ ) was weighed into a

Table 1. Preparation of soaked hair samples

\begin{tabular}{lccccc}
\hline & \multicolumn{2}{c}{ COC } & & \multicolumn{2}{c}{ BEG } \\
\cline { 2 - 3 } \cline { 5 - 6 } Level & Solution & Hair & & Solution & Hair \\
\hline 1 & 3.2 & $0.44 \pm 0.07$ & & 2 & $0.79 \pm 0.09$ \\
2 & 16 & $3.72 \pm 0.43$ & & 4 & $1.47 \pm 0.18$ \\
3 & 32 & $5.54 \pm 0.54$ & & 8 & $3.33 \pm 0.34$ \\
\hline
\end{tabular}

Concentrations in $\mu \mathrm{g} / \mathrm{mL}$ (solution) and $\mathrm{ng} / \mathrm{mg}$ (hair).

Mean concentrations in hair and respective standard deviations. 
$10 \mathrm{~mL}$ glass tube; $2 \mathrm{~mL}$ of methanol and $1 \mathrm{~mL}$ of $0.1 \mathrm{M}$ hydrochloric acid were added and the mixture was heated for $3 \mathrm{~h}$ at $65^{\circ} \mathrm{C}$.

\section{Sample cleanup}

The tubes were centrifuged at $3500 \mathrm{rpm}$ for $5 \mathrm{~min}$, after which time the supernatant was transferred to another tube and neutralized with $25 \mu \mathrm{L}$ of a $4 \mathrm{M}$ sodium hydroxide solution. After addition of $20 \mu \mathrm{L}$ of a standard mixture of the internal standards at $10 \mu \mathrm{g} / \mathrm{mL}$, the excess methanol was evaporated at $45^{\circ} \mathrm{C}$ under a gentle stream of $\mathrm{N}_{2}$. Then $5 \mathrm{~mL}$ of $0.1 \mathrm{M} \mathrm{KH}_{2} \mathrm{PO}_{4}$ were added, and the mixture was homogenized for $15 \mathrm{~min}$ by rotation/inversion movements.

For sample cleanup, this homogenate was added to mixedmode SPE cartridges, previously conditioned with $2 \mathrm{~mL}$ of methanol and $2 \mathrm{~mL}$ of deionized water. After the sample had passed through, the cartridges were washed sequentially with $2 \mathrm{~mL}$ of each of the following: deionized water, $0.1 \mathrm{M}$ hydrochloric acid, dichloromethane/methanol (50:50, v/v) and n-hexane. After drying under full vacuum for $1 \mathrm{~min}$, the analytes were eluted with $2 \mathrm{~mL}$ of a mixture of dichloromethane/isopropanol (80:20, v/v) with $2 \%$ of ammonium hydroxide.

The extracts were dried at $45^{\circ} \mathrm{C}$ under a gentle stream of $\mathrm{N}_{2}$. MSTFA with $5 \%$ of CTMS $(50 \mu \mathrm{L})$ was added, and, after vortex mixing for $30 \mathrm{~s}$, derivatization took place at $80^{\circ} \mathrm{C}$ for $25 \mathrm{~min}$. The extracts were transferred to autosampler vials, and a $2 \mu \mathrm{L}$ aliquot was injected into the chromatographic system.

\section{RESULTS AND DISCUSSION}

\section{Optimization of drug extraction from within the matrix}

The most time-consuming step in hair analysis for drugs is their extraction. Drugs are entrapped within the matrix, and must be effectively and quantitatively extracted in order to obtain reproducible and accurate results. For this reason, soaked hair was used in these optimization experiments, since it reproduces more adequately the hair of a drug user. The hair was soaked with cocaine alone, so that the conversion of cocaine into benzoylecgonine due to the extraction conditions could be studied. All the optimization experiments were performed in triplicate.

Preliminary experiments were conducted in order to obtain the best solvent or mixture to accomplish drug extraction from hair, using $3 \mathrm{~mL}$ of either methanol, $0.1 \mathrm{M}$ $\mathrm{HCl}$, or methanol/0.1 M HCl (2:1). These experiments were performed in triplicate, using an overnight (approximately $18 \mathrm{~h}$ ) extraction at $65^{\circ} \mathrm{C}$. As can be seen in Fig. 1, area counts when using the mixture of both solvents were higher than using the solvents individually. Therefore, methanol/ $0.1 \mathrm{M} \mathrm{HCl}$ (2:1) was used in the remaining optimization experiments.

The extraction of drugs from within the hair matrix must be thorough, and, therefore, the extraction time is a crucial feature in method development. To find the best extraction time, $3 \mathrm{~mL}$ of methanol/0.1 M HCl (2:1) were added to $20 \mathrm{mg}$ of finely divided soaked hair. The samples were extracted at $65^{\circ} \mathrm{C}$ for several controlled time intervals $(1,2,3,5$ and $18 \mathrm{~h})$.

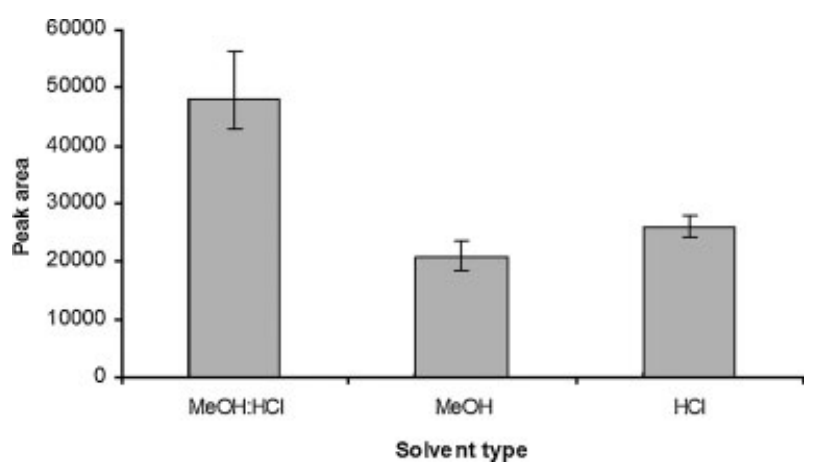

Figure 1. Effect of the extraction solvent on the extracted amount of cocaine.

Faster extractions (30 and $60 \mathrm{~min}$ ) at higher temperatures (80 and $120^{\circ} \mathrm{C}$ ) were also studied.

After each extraction time, the samples were neutralized with $4 \mathrm{M}$ sodium hydroxide and subjected to the abovementioned cleanup procedure. To establish the extraction time profile, area counts obtained for each extraction time were plotted against the extraction time. As could be expected, an increase in the extracted amount was observed when the extraction time increased, reaching a maximum at $3 \mathrm{~h}$. Longer periods of extraction at this temperature, including an overnight extraction, did not significantly improve the extraction yield (Fig. 2).

On the other hand, increasing the extraction temperature in order to obtain shorter extraction times was not possible, as there was a significant conversion of cocaine into benzoylecgonine. Therefore, the chosen extraction conditions were $3 \mathrm{~h}$ at $65^{\circ} \mathrm{C}$, which is a considerably shorter extraction time than in other published methods. ${ }^{14,15,19,25-28,40-42}$

\section{Validation procedure}

The analytical method validation was performed in accordance with the guidelines of the $\mathrm{FDA}^{43}$ and the $\mathrm{ICH}^{44}$ and the studied parameters were selectivity/specificity, linearity, limits of detection and quantitation, repeatability, intermediate precision, accuracy and recovery.

\section{Selectivity/specificity}

To study method selectivity, a pool of blank hair was prepared by mixing hair from five different individuals

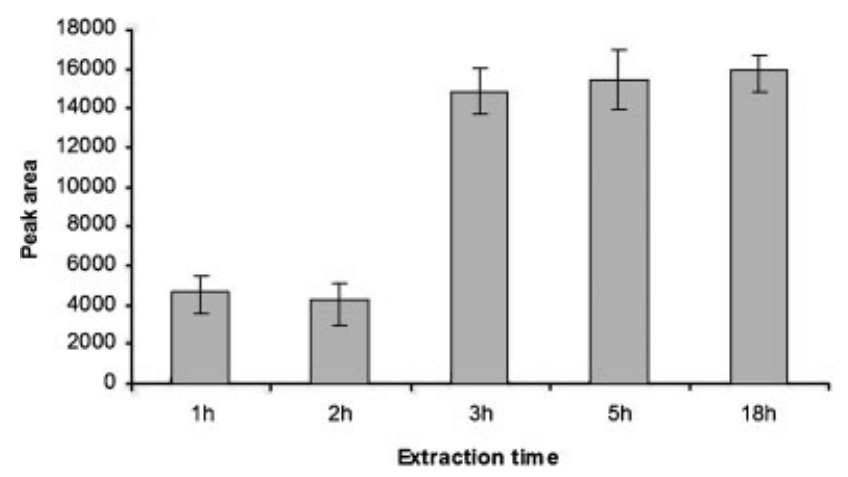

Figure 2. Effect of the extraction time on the extracted amount of cocaine.

Rapid Commun. Mass Spectrom. 2008; 22: 3320-3326 
(laboratory personnel). From this pool, 20 aliquots of $20 \mathrm{mg}$ each were weighed into $10 \mathrm{~mL}$ glass tubes. Ten of these aliquots were spiked with cocaine and benzoylecgonine at $5 \mathrm{ng} / \mathrm{mg}$ of hair. All the samples were extracted for $3 \mathrm{~h}$ at $65^{\circ} \mathrm{C}$, after which time they were neutralized with $4 \mathrm{M}$ sodium hydroxide, and $20 \mu \mathrm{L}$ of a mixture of the deuterated analogues of both compounds were added to each tube. The above-mentioned cleanup procedure was applied to each sample, and the obtained chromatograms were compared. Both cocaine and benzoylecgonine were successfully identified in all the spiked hair samples (both in terms of ion ratios and relative retention time). On the other hand, no interfering peaks were observed at the retention times and at the $\mathrm{m} / \mathrm{z}$ values of the selected ions of cocaine and benzoylecgonine after analysis of the negative samples, which means that hair constituents did not interfere significantly with the studied analytes. Therefore, the described method was considered selective and specific for the determination of cocaine and benzoylecgonine in hair samples (Figs. 3 and 4).

\section{Calibration curves and limits}

To evaluate the linearity of the method, hair digests spiked at final concentrations ranging from 0.05 to $20 \mathrm{ng} / \mathrm{mg}$ (eight calibrators, five replicates) were prepared and analyzed by the described procedure. Along with each calibration curve, a zero sample (blank sample with internal standard) and three QC samples were also analyzed.

Calibration curves were obtained by plotting the peak-area ratio between the analyte and internal standard against analyte concentration. Using a weighted $(1 / x)$ least-squares regression, a linear relationship was obtained for both compounds, and the accuracy of the calibrators [mean relative error (bias) between measured and spiked concentrations] was within $\pm 16 \%$ of the true values for cocaine and

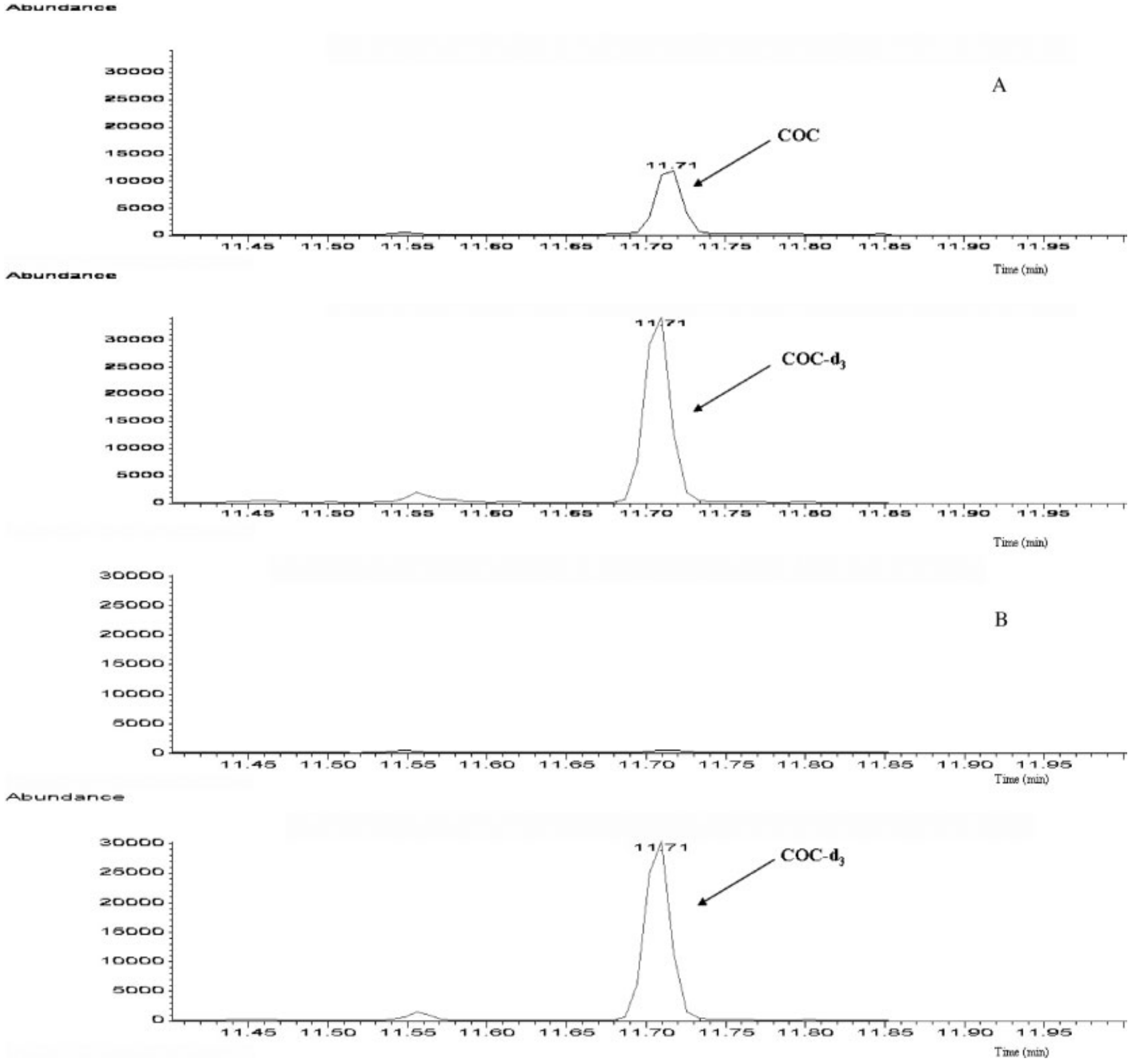

Figure 3. Merged fragmentogram (ion 182) of a soaked hair sample (2.84 ng/mg; A) and a blank hair sample (B) for cocaine. 


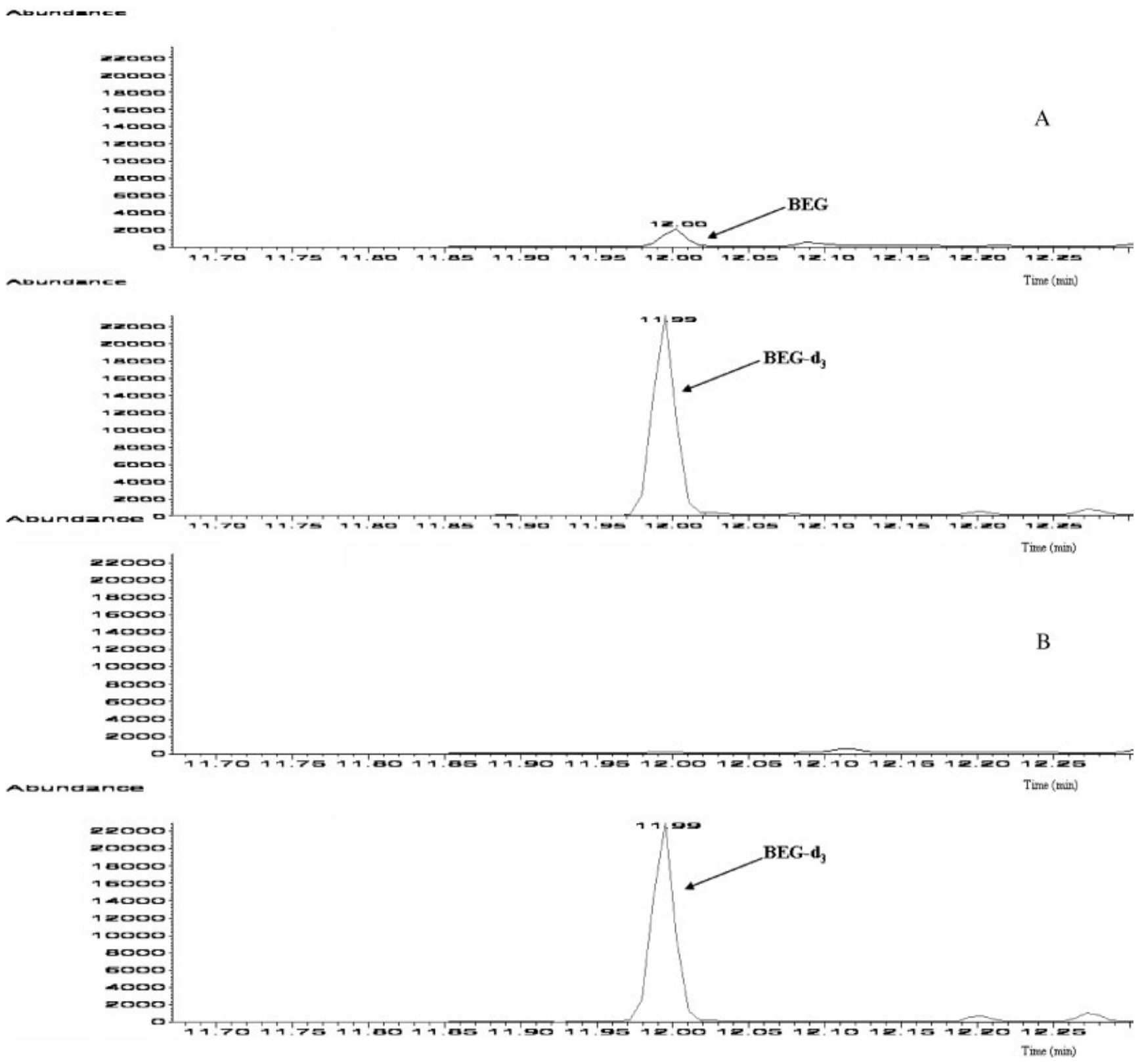

Figure 4. Merged fragmentogram (ion 240) of a soaked hair sample $(1.13 \mathrm{ng} / \mathrm{mg} ; A$ ) and a blank hair sample (B) for benzoylecgonine.

$\pm 13 \%$ for benzoylecgonine. The calibration data is shown in Table 2.

The limits of quantitation (LOQs), defined as the lowest concentrations of analyte that could be measured reproducibly and accurately (coefficient of variation (CV) $<20 \%$ and bias $\pm 20 \%$ ), were determined by analyzing six replicates of spiked hair digests (independent from those of the calibration curve) and were $50 \mathrm{pg} / \mathrm{mg}$ for both compounds. The limits of detection (LODs), defined as the lowest tested concentrations yielding a signal-to-noise ratio of at least 3 , were 20 and $15 \mathrm{pg} / \mathrm{mg}$ for cocaine and benzoylecgonine, respectively. These quite low limits were obtained using only $20 \mathrm{mg}$ of sample, which means that this reduced amount of sample does not limit the usefulness of the

Table 2. Calibration data

\begin{tabular}{|c|c|c|c|c|c|c|}
\hline & \multirow[b]{2}{*}{ Linear range (ng/mg) } & \multicolumn{2}{|c|}{ Linearity } & \multirow[b]{2}{*}{$\mathrm{R}^{2}$} & \multirow[b]{2}{*}{ LOD (pg/mg) } & \multirow[b]{2}{*}{ LOQ (pg/mg) } \\
\hline & & slope & intercept & & & \\
\hline Benzoylecgonine & $0.05-20$ & $0.1071 \pm 0.011$ & $0.0083 \pm 0.00505$ & $0.9987 \pm 0.0003$ & 15 & 50 \\
\hline
\end{tabular}


Table 3. Repeatability data $(n=7)$

\begin{tabular}{|c|c|c|c|c|c|c|c|}
\hline \multicolumn{4}{|c|}{ Cocaine } & \multicolumn{4}{|c|}{ Benzoylecgonine } \\
\hline Spiked & Found & $\mathrm{CV}(\%)$ & RE (\%) & Spiked & Found & CV (\%) & RE (\%) \\
\hline 0.05 & 0.05 & 10.93 & -8.25 & 0.05 & 0.05 & 5.95 & 3.61 \\
\hline 0.50 & 0.44 & 13.13 & -12.02 & 0.50 & 0.46 & 3.76 & -8.51 \\
\hline 7.50 & 6.41 & 6.05 & -14.52 & 7.50 & 6.82 & 6.29 & -9.02 \\
\hline 17.50 & 17.21 & 3.57 & -1.66 & 17.50 & 17.52 & 3.66 & 0.11 \\
\hline
\end{tabular}

$\mathrm{CV}$ : coefficient of variation; RE: relative error [(spiked concentration nominal concentration/nominal concentration) $\times 100$ ]; All concentrations in $\mathrm{ng} / \mathrm{mg}$ of hair.
Table 5. Sample cleanup efficiency (\%) at four concentrations

\begin{tabular}{lrrr}
\hline & \multicolumn{1}{c}{ COC } & \multicolumn{1}{c}{ BEG } \\
\cline { 2 - 2 } Concentration ng/mg & Recovery & & Recovery \\
\hline 0.05 & $99.2 \pm 0.03$ & & $97.7 \pm 0.09$ \\
0.50 & $106.7 \pm 0.05$ & & $102.7 \pm 0.04$ \\
7.50 & $92.5 \pm 0.06$ & & $90.9 \pm 0.01$ \\
17.50 & $98.4 \pm 0.03$ & & $96.9 \pm 0.05$ \\
\hline
\end{tabular}

Mean values and standard deviations.

Table 4. Intermediate precision and accuracy data

\begin{tabular}{|c|c|c|c|c|c|c|c|c|}
\hline \multirow[b]{2}{*}{ Level } & \multicolumn{4}{|c|}{$\mathrm{COC}$} & \multicolumn{4}{|c|}{ BEG } \\
\hline & $\mathrm{CSH} \mathrm{ng} / \mathrm{mg}$ & Found ng/mg & RE \% & $\mathrm{CV} \%$ & $\mathrm{CSH}$ ng/mg & Found ng/mg & $\mathrm{RE} \%$ & $\mathrm{CV} \%$ \\
\hline 1 & 0.44 & 0.43 & -3.38 & 11.7 & 0.79 & 0.78 & -1.01 & 9.4 \\
\hline 2 & 3.72 & 3.72 & -0.07 & 9.0 & 1.47 & 1.49 & 1.15 & 10.5 \\
\hline 3 & 5.54 & 5.62 & 1.46 & 8.6 & 3.33 & 3.35 & 0.65 & 10.3 \\
\hline
\end{tabular}

CSH: concentration in soaked hair; CV: coefficient of variation; RE: relative error [(spiked concentration - nominal concentration/nominal concentration) $\times 100]$.

technique, complying with the cut-off values proposed by the Society of Hair Testing for cocaine analysis in hair ( 0.5 and $0.05 \mathrm{ng} / \mathrm{mg}$ for cocaine and benzoylecgonine, respectively). Furthermore, these limits are similar to or even lower than those presented in other published methods. ${ }^{19,28,38,40}$

In addition, the fact that low limits are achieved using this small amount of hair may be important in situations where there is little available sample, and/or segmental analysis is required.

\section{Repeatability, intermediate precision and accuracy}

The repeatability was evaluated at four concentration levels for both compounds $(0.05,0.5,7.5$ and $17.5 \mathrm{ng} / \mathrm{mg}$ ) using spiked samples prepared and analyzed as mentioned above (seven replicates for each concentration). The obtained CVs were lower than $14 \%$ for both compounds at all concentrations, presenting a relative error [(spiked concentration - nominal concentration/nominal concentration) $\times$ $100]$ within a $\pm 15 \%$ interval. These results are presented in Table 3.

The intermediate precision and accuracy were evaluated using the above-mentioned $\mathrm{QC}$ samples (their respective concentrations are shown in Table 1) analyzed in triplicate on five different days over a 30-day period. The calculated CVs (combined intra- and interday) were lower than $12 \%$ for both compounds, while accuracy (in terms of relative error) was within a $\pm 4 \%$ interval. These data are presented in Table 4.

\section{Absolute recovery (sample cleanup step)}

The absolute recovery of the sample cleanup step was determined by triplicate analysis of samples spiked at four concentrations $(0.05,0.5,7.5$ and $17.5 \mathrm{ng} / \mathrm{mL})$, in which the internal standards were only added after that procedure. The obtained peak area ratios were compared with those obtained by spiking blank extracts with the same amounts of both compounds (100\% recovery). Recovery data are presented in Table 5 .

\section{Application to authentic samples}

After validation, the procedure was applied to 16 postmortem authentic samples obtained from autopsies performed at the National Institute of Legal Medicine, Lisbon, Portugal (Table 6). Figure 5 shows a typical chromatogram of

Table 6. Application to authentic samples

\begin{tabular}{rrr}
\hline Sample \# & COC & BEG \\
\hline 1 & 0.64 & 0.60 \\
2 & 15.02 & 14.99 \\
3 & 6.47 & 3.68 \\
4 & 12.47 & 11.35 \\
5 & 1.13 & 1.76 \\
6 & 27.41 & 33.09 \\
7 & 99.40 & 50.31 \\
8 & 0.62 & 0.58 \\
9 & 2.79 & 2.15 \\
10 & 43.76 & 20.48 \\
11 & 3.67 & 3.47 \\
12 & 182.88 & 44.52 \\
13 & 65.09 & 14.68 \\
14 & 16.24 & 2.54 \\
15 & 2.03 & 0.57 \\
16 & 3.80 & 0.45 \\
\hline
\end{tabular}

All concentrations in $\mathrm{ng} / \mathrm{mg}$ of hair.

Rapid Commun. Mass Spectrom. 2008; 22: 3320-3326 DOI: $10.1002 / \mathrm{rcm}$ 


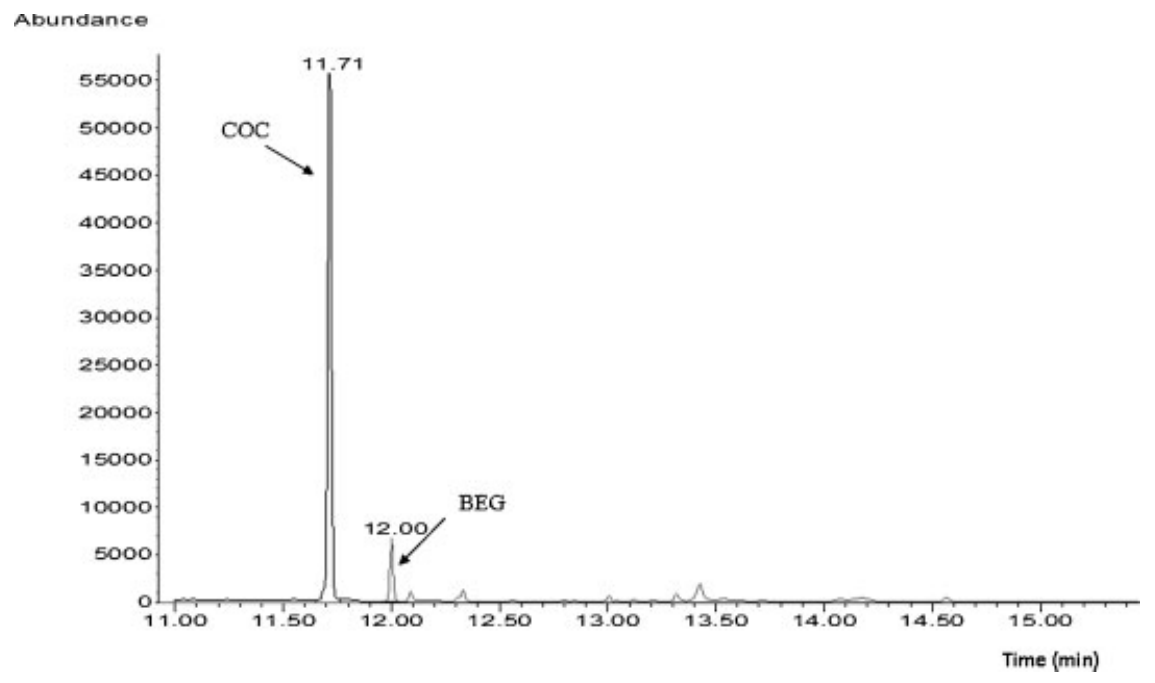

Figure 5. Ion chromatogram (ion 182 for cocaine and 240 for benzoylecgonine) of an authentic sample (sample \#14).

an authentic sample (sample \#14; 16.24 and $2.54 \mathrm{ng} / \mathrm{mg}$ for cocaine and benzoylecgonine, respectively).

\section{CONCLUSIONS}

We have developed a simple and rapid method for the quantitative determination of cocaine and benzoylecgonine in hair samples. The procedure was sensitive and specific enough to detect 20 and $15 \mathrm{pg} / \mathrm{mg}$ of cocaine and benzoylecgonine, using only $20 \mathrm{mg}$ of sample. It has been completely validated, showing excellent results for all the studied parameters. Furthermore, the developed method may be useful in forensic toxicology laboratories for the analysis of these compounds in hair samples, taking into account its speed (only $3 \mathrm{~h}$ are required for the extraction of the analytes from within the matrix, while extraction times of $5 \mathrm{~h}$ or even $18 \mathrm{~h}$ have been reported for previous studies) and the fact that such low limits were achieved using a single quadrupole mass spectrometer.

\section{REFERENCES}

1. Gallardo E, Queiroz JA. Biomed. Chromatogr. 2008; 22: 795.

2. Kintz P, Samyn N. Ther. Drug Monit. 2002; 24: 239.

3. Kintz P, Villain M, Cirimele V. Ther. Drug Monit. 2006; 28: 442.

4. Pragst F, Balikova MA. Clin. Chim. Acta 2006; 370: 17.

5. Caplan YH, Goldberger BA. J. Anal. Toxicol. 2001; 25: 396.

6. Cairns T, Hill V, Schaffer M, Thistle W. Forensic Sci. Int. 2004; 145: 175 .

7. Kintz P. Anal. Bional. Chem. 2007; 388: 1467.

8. Negrusz A, Gaensslen RE. Anal. Bioanal. Chem. 2003; 376: 1192.

9. Society of Hair Testing. Forensic Sci. Int. 2004; 145: 83.

10. Gambelunghe C, Rossi R, Ferranti C, Rossi R, Bacci M. J. Appl. Toxicol. 2005; 25: 205.

11. Pichini S, Pacifici R, Altieri I, Pellegrini M, Zuccaro P. J. Anal. Toxicol. 1999; 23: 343.

12. Uhl M. Forensic Sci. Int. 1997; 84: 281.

13. Uhl M. Forensic Sci. Int. 2000; 107: 169.

14. Romolo FS, Rotolo MC, Palmi I, Pacifici R, Lopez A. Forensic Sci. Int. 2003; 138: 17.

15. Kronstrand R, Nyström I, Strandberg J, Druid H. Forensic Sci. Int. 2004; 145: 183.

16. Harkey MR, Henderson GL, Zhou C. J. Anal. Toxicol. 1991; 15: 260

Copyright (C) 2008 John Wiley \& Sons, Ltd.
17. Strano-Rossi S, Chiarotti M. J. Anal. Toxicol. 1999; 23 : 7.

18. Ropero-Miller JD, Goldberger BA, Cone EJ, Joseph RE Jr. J. Anal. Toxicol. 2000; 24: 496.

19. Bermejo AM, López P, Álvarez I, Tabernero MJ, Fernández P. Forensic Sci. Int. 2006; 156: 2.

20. Mieczkowski T, Kruger M. J. Forensic Leg. Med. 2007; 14: 7.

21. Kintz P, Mangin P. Forensic Sci. Int. 1995; 73: 93.

22. Cirimele V, Kintz P, Mangin P. Biomed. Chromatogr. 1996; 10: 179.

23. Wang WL, Darwin WD, Cone EJ. J. Chromatogr. B 1994; 660: 279.

24. Girod C, Staub C. Forensic Sci. Int. 2000; 107: 261.

25. Cognard E, Rudaz S, Bouchonnet S, Staub C. J. Chromatogr. B 2005; 826: 17

26. Gottardo R, Bortolotti F, De Paoli G, Pascali JP, Mikšík I, Tagliaro F. J. Chromatogr. A 2007; 1159: 185.

27. Cristoni S, Basso E, Gerthoux P, Mocarelli P, Gonella E, Brambilla M, Crotti S, Bernardi R. Rapid Commun. Mass Spectrom. 2007; 21: 2515.

28. Cordero R, Paterson S. J. Chromatogr. B 2007; 850: 423.

29. Musshoff F, Madea B. Anal. Bional. Chem. 2007; 388: 1475.

30. Tsanaclis L, Wicks JF. Forensic Sci. Int. 2008; 176: 19.

31. Paterson S, McLachlan-Troup N, Cordero R, Dohnal M, Carman S. J. Anal. Toxicol. 2001; 25: 203.

32. Fritch D, Groce Y, Rieders F. J. Anal. Toxicol. 1992; 16: 112.

33. Moeller MR, Fey P, Wenning R. Forensic Sci. Int. 1993; 63: 185.

34. Kronstrand R, Grundin R, Jonsson J. Forensic Sci. Int. 1998; 92: 29.

35. Segura J, Stramesi C, Redon A, Ventura M, Sanchez CJ, Gonzalez G, San L, Montagna M. J. Chromatogr. A 1999; 724: 9.

36. Scheidweiler KB, Huestis MA. Anal. Chem. 2004; 76: 4358.

37. Moore C, Coulter C, Crompton K. J. Chromatogr. B 2007; 859: 208.

38. de Toledo FC, Yonamine M, de Moraes Moreau RL, Silva OA. J. Chromatogr. B 2003; 798: 361.

39. Morrison JF, Chesler SN, Yoo WJ, Selevka CM. Anal. Chem. 1998; 70: 163

40. Stramesi C, Polla M, Vignali C, Zucchella A, Groppi A. Forensic Sci. Int. 2008; 176: 34.

41. Cingolani M, Scavella S, Mencarelli R, Mirtella D, Froldi R, Rodriguez D. J. Anal. Toxicol. 2004; 28: 128.

42. Hegstad S, Khiabani HZ, Kristoffersen L, Kunøe N, Lobmaier PP, Christophersen AS. J. Anal. Toxicol. 2008; 32: 36.

43. Food and Drug Administration: U.S. Department of Health and Human Services, Guidance for Industry, Bioanalytical Method Validation. FDA [document online] [cited 21 January 2003]. Available: www.fda.gov/cder/guidance/4252fnl.pdf.

44. International Conference on Harmonization (ICH), Validation of Analytical Procedures: Methodology ICH Q2 B. ICH [document online] [cited 21 January 2003]. Available: www.ich.org/MediaServer.jser?@_ID=4188@_MODE=GLB. 